\title{
Low expression of MSH2 DNA repair protein is associated with poor prognosis in head and neck squamous cell carcinoma
}

\author{
Camila Santos PEREIRA ${ }^{1}$, Marcos Vinícius Macedo de OLIVEIRA ${ }^{1}$, Lucas Oliveira BARROS ${ }^{1}$, Gabriela Alencar \\ BANDEIRA ${ }^{1}$, Sérgio Henrique Sousa SANTOS ${ }^{1,2}$, John R. BASILE ${ }^{3}$, André Luiz Sena GUIMARÃES ${ }^{1,4}$, Alfredo Maurício \\ Batista DE PAULA ${ }^{1,4}$
}

\author{
1- Nucleus of Epidemiological and Molecular Research Catrumano. Health Research Laboratory Health Science Post-Graduate Programme. Universidade \\ Estadual de Montes Claros, Montes Claros, MG, Brazil. \\ 2- Department of Pharmacology, Universidade Federal de Minas Gerais, Belo Horizonte, MG, Brazil. \\ 3- Department of Oncology and Diagnostic Sciences, University of Maryland Dental School, Baltimore, MD, United States. \\ 4- Department of Dentistry, Universidade Federal de Minas Gerais, Belo Horizonte, MG, Brazil.
}

Corresponding address: Alfredo Maurício Batista De Paula - Laboratório de Pesquisa Saúde - Hospital Universitário Clemente de Faria - Universidade Estadual de Montes Claros - Unimontes - Av. Cula Mangabeira, 562 - Santo Expedito - Montes Claros - MG - Brazil - 39401-001 - Phone: 55-21-38 32248327 - Fax: 55-21-38 32298500 - e-mail: ambpatologi@gmail.com

Submitted: March 15, 2013 - Modification: May 14, 2013 - Accepted: May 23, 2013

\section{ABSTRACT}

\begin{abstract}
bjective: This study aimed to investigate the expression of the MSH2 DNA repair protein in head and neck squamous cell carcinoma (HNSCC) in order to analyze its association with clinicopathologic factors and overall survival of patients. Material and Methods: Clinical data and primary lesions of HNSSC were collected from 55 patients who underwent surgical resection with postoperative radiotherapy in Montes Claros, state of Minas Gerais, Brazil, between 2000 and 2008. Immunohistochemical reactions were performed to analyze MSH2 protein expression. Results: Bivariate analysis showed no significant correlation or association between MSH2 expression and clinicopathologic parameters by Mann-Whitney and Kruskal-Wallis tests. Patients with locoregional metastatic disease $(O R=4.949, p \leq 0.001)$ and lower MSH2 immunohistochemical expressions $(\mathrm{OR}=2.943, \mathrm{p}=0.032)$ presented poorer survival for HNSCC by Cox regression models. Conclusions: Our data demonstrated that lower MSH2 expression might contribute to a higher clinic aggressiveness of HNSCC by promoting an unfavorable outcome.
\end{abstract}

Keywords: Squamous cell carcinoma. DNA repair. MutS homolog 2 protein. Immunohistochemistry. Prognosis.

\section{INTRODUCTION}

Head and neck squamous cell carcinoma (HNSCC) is the most prevalent malignant neoplasm arising from the epithelial lining of the upper aerodigestive tract mucosa. It represents the $6^{\text {th }}$ most common type of human cancer, and it is responsible for high death rates worldwide every year ${ }^{4,10}$. A plethora of sociodemographic, economic, and cultural factors are associated with the development of HNSCC, along with a background of molecular disturbances, both genetic and epigenetic, that influence the course and incidence of the disease ${ }^{1,8}$.

Mismatch repair (MMR) is responsible for mismatch base substitution and insertion-deletion mismatches generated during DNA replication. MMR also recognizes DNA damage formed by chemical compounds, such as alkylating agents. Inactivation of MMR genes and proteins can have profound biological consequences on cells such as an increased tendency of mutations in genes associated with maintenance and replication of genome ${ }^{14,20}$. A crucial part of this system is the MutS-homologue 2 (MSH2) gene, which is located at chromosome $2 \mathrm{p} 22$. MSH2 protein recognizes DNA mismatches by forming two functional heterodimers: $\mathrm{MSH} 2-\mathrm{MSH} 6$, and $\mathrm{MSH} 2-\mathrm{MSH} 3$. MSH2-MSH6 recognizes single-base mismatches and short insertion-deletion loops, and MSH2-MSH3 which recognizes larger loops that occur during DNA 
replication 6,22 .

Disorders in MMR results in microsatellite instability and the accumulation of mutations in proto-oncogenes or tumor suppressor genes which can lead to cancer development. Moreover, it has been observed that tumors with loss of MSH2 expression showed increased frequency of microsatellite instability ${ }^{23,24 .}$ This mechanism is characterized by small insertions or deletions within short tandem repeats in tumor DNA when compared with the corresponding normal DNA ${ }^{2}$. Tumors with MSI frequently show somatic alterations in repetitive DNA tracts of several genes involved in cell growth control, apoptosis, and DNA repair $7,27,29$.

Molecular disturbances in the repair mechanisms mediated by the $\mathrm{MSH} 2$ repair confer susceptibility on tumor cells to present somatic mutations throughout the genome. Furthermore, these alterations in expression of $\mathrm{MSH} 2$ have been associated with chromosomal or genomic instability which, at a molecular level, might predispose to $\mathrm{HNSCC}^{7,29}$. However, little is known about the role of $\mathrm{MSH} 2$ in prognostic of patients with HNSCC. The aim of this study was to investigate the expression of the MSH2 DNA repair protein in the carcinoma cells of HNSCC in order to analyze its association with clinicopathologic factors and overall survival of patients.

\section{MATERIAL AND METHODS}

\section{Tissue specimens, patients, and ethical aspects}

This retrospective analytical study was performed using archived tissue blocks from 55 surgically resected primary lesions from patients with HNSCC, confirmed by morphological analysis (male-tofemale ratio, $4.5: 1$; mean age, $61.2 \pm 12.9$ years). All selected patients underwent surgical resection followed by postoperative radiotherapy. Clinical and outcome data from the HNSCC patients were obtained from the health records at reference centers for diagnosis and oncology treatment between 2000 and 2008 in Montes Claros, Minas Gerais, Brazil. Ethical approval for this study was obtained from the relevant local ethics committees (Unimontes: 1564/2008).

\section{Clinical staging}

HNSCC tumors were classified according to the International Union Against Cancer TNM Classification of Malignant Tumors and the International Classification of Diseases for Oncology ${ }^{26}$. TNM staging resulted in the following distribution: stage I, 1 patient $(1.8 \%)$; stage II, 4 (7.3\%); stage III, 23 (41.8\%); and stage IV, 27 $(49.1 \%)$. The anatomical site of HNSCC lesions were distributed in oral cavity $(n=19,34.5 \%)$, oropharynx ( $n=23,41,8 \%)$, hypopharynx $(n=5$, $9.1 \%)$, and larynx $(n=8,14.5 \%)$. The lesions located in the oral cavity were considered as the anterior group and those located in the oropharynxhypopharynx-larynx as the posterior group for characterization of the anatomical site variable. Clinical factors were classified as follows: local recurrence: absence $(n=38,69.1 \%)$ and presence $(n=17,30.9 \%)$; tumor size: small lesions (T1/ $T 2, n=8,14.5 \%)$ and large lesions (T3/T4, $n=47$, $85.5 \%)$; locoregional metastasis: absent ( $n=24$, $43.6 \%)$ and present $(n=31,56.4 \%)$; distant metastasis: absent $(n=51,92.7 \%)$ and present $(n=4,2.3 \%)$.

\section{Morphological staging}

Paraffin-embedded archival tissue from primary HNSCC were cut in $5 \mu \mathrm{m}$ thick sections, deparaffinized, and stained with hematoxylin and eosin. Only specimens with clear morphological evidence of tumor infiltration into the connective tissue were included. Morphological analysis was carried out by an oral pathologist (AMB de Paula) with no prior knowledge of the epidemiological or clinical data of the selected patients. Kappa statistic was used to assess intra-examiner reproducibility (AMB de Paula) relating to morphological grades of OSCC. Kappa test revealed good concordance for OSCC groups (WHO, 1995, $k=0.877, p=0.000$; Invasive Front Grading, $k=0.492, p=0.024)$. All HNSCC samples were reviewed and graded using the cell differentiation degrees of the World Health Organization (WHO ${ }^{21}$ and Invasive Front Grading $(\mathrm{IFG})^{3}$. In these morphological grading systems, high malignancy scores are considered to be representative of a poorly differentiated tumor and exhibited evidence of morphological severity, such as absence or decreased keratinization, high cell dissociation, and diffuse infiltrative pattern. The lesions were morphologically classified as follows: well/moderately differentiated (I/II) vs. poorly differentiated (III) (WHO grading) and accordingly with IFG, the grading was classified into three groups: $F 1$ (4-8 points), F2 ( $9-12$ points) and F3 (13-16 points). Higher scores for IFG have been associated with greater clinicopathologic aggressiveness of malignant disease.

\section{Immunohistochemical (IHC) analysis}

HNSCC sections were deparaffinized in xylene and rehydrated in a series of descending ethanol concentrations. Thereafter, the sections were treated in a pressure boiler with TRIS EDTA $(\mathrm{pH}=7.4)$ for $5 \mathrm{~min}$ at $121^{\circ} \mathrm{C}$. The sections were submitted to 5 min blocking with endogenous peroxidase and $0.03 \%$ hydrogen peroxide in $100 \%$ ethanol. After washing with $10 \mathrm{mM}$ phosphatebuffered saline (PBS) $(\mathrm{pH}=7.6)$ for $5 \mathrm{~min}$, the 
sections were incubated with Protein Block Serumfree (Dako, California, USA) prior to incubation with primary antibodies overnight at $4^{\circ} \mathrm{C}$. The primary antibody used was mouse monoclonal anti-MSH2 (dilution 1:80; clone 25D12, Abcam, Cambridge, USA). The sections were thereafter incubated with streptavidin-biotin labeled antibody (LSAB-Kit Plus Peroxidase; Dako, California, USA) for $30 \mathrm{~min}$. Tissues were stained for $5 \mathrm{~min}$ with 3,3'-diaminobenzidine tetrahydrochloride freshly prepared in $10 \mathrm{mM}$ PBS containing $0.1 \%$ hydrogen peroxide and then counterstained with Mayer's hematoxylin and mounted in Permount (Fisher
Scientific, New Jersey, USA). Positive control was applied according to the manufacturer's instructions, and negative controls were employed by replacing the primary antibody with Universal Negative Control (Dako, California, USA).

\section{Counting of immunostained samples}

Samples were evaluated by one independent observer using an optical Olympus ${ }^{\circledR} \mathrm{BH} 2$ microscope (model: CX31; RTSF, Miami, USA), with 10x ocular and 40x objective lenses and an ocular lattice (area: $0.092 \mathrm{~mm}^{2}$ ). Counting of 12 fields in the invasive front of HNSCC was performed to calculate

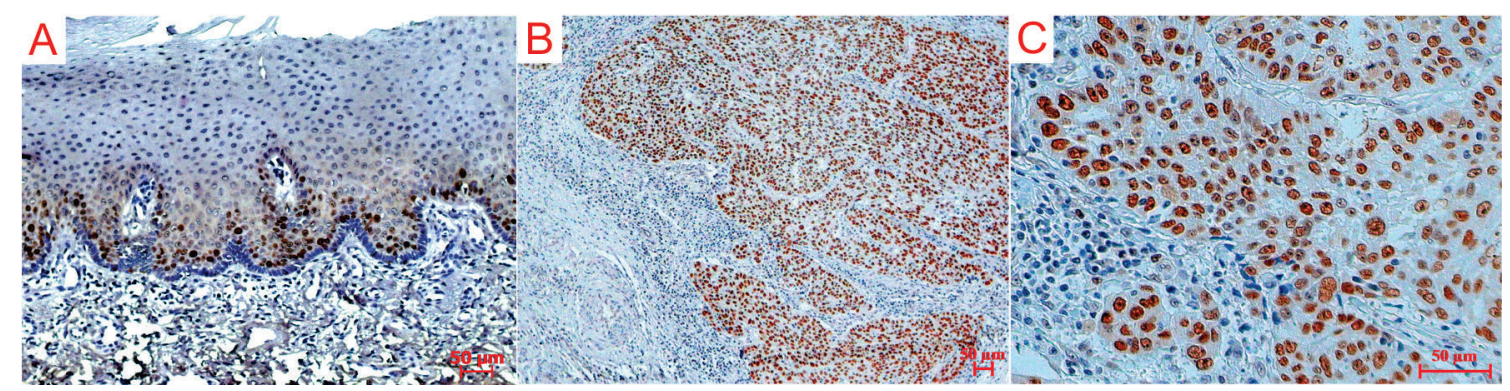

Figure 1- Immunohistochemical expression of MSH2 repair protein in healthy oral mucosa and carcinoma cells of the invasive front of head and neck squamous cell carcinoma (HNSCC). A: Low immunohistochemical expression in basal layer of oral healthy epithelium. B/C: High immunohistochemical expression cases of HNSCC. Slides were stained with diaminobenzidine and counterstained with Mayer's haematoxylin

Table 1- Bivariate analysis between the clinicopathologic covariates and the mean values of MSH2 immunohistochemical expression in the head and neck squamous cell carcinoma samples

\begin{tabular}{|c|c|c|}
\hline \multicolumn{3}{|c|}{ DNA Repair Proteins Immunoexpression } \\
\hline Covariates & $\mathrm{MSH} 2$ & \\
\hline Anatomical Site & Mean $\pm S D$ & $\mathrm{p}$ \\
\hline Anterior $(n=20)$ & $80.77 \pm 22.10$ & 0.523 \\
\hline Posterior $(n=35)$ & $81.92 \pm 21.49$ & \\
\hline \multicolumn{3}{|l|}{ Recurrence } \\
\hline Absent $(n=38)$ & $81.15 \pm 20.17$ & 0.449 \\
\hline Present $(n=17)$ & $82.28 \pm 24.90$ & \\
\hline \multicolumn{3}{|l|}{ Tumor Size } \\
\hline Small $(n=8)$ & $89.85 \pm 8.25$ & 0.317 \\
\hline Large $(n=47)$ & $80.08 \pm 22.78$ & \\
\hline \multicolumn{3}{|l|}{ Locorregional Metastasis } \\
\hline Absent $(n=24)$ & $79.90 \pm 26.56$ & 0.946 \\
\hline Present $(n=31)$ & $82.74 \pm 16.99$ & \\
\hline \multicolumn{3}{|l|}{ WHO Grading } \\
\hline Well/Moderate differentiated $(n=39)$ & $85.21 \pm 14.61$ & 0.339 \\
\hline Poorly differentiated $(n=16)$ & $72.45 \pm 31.66$ & \\
\hline \multicolumn{3}{|l|}{ IFG } \\
\hline $4-8(n=6)$ & $87.95 \pm 16.12$ & 0.509 \\
\hline $9-12(n=22)$ & $77.85 \pm 25.36$ & \\
\hline $13-16(n=27)$ & $83.04 \pm 19.20$ & \\
\hline
\end{tabular}


the percentage of positive carcinoma cells. Only carcinoma cells with a distinct brown staining of the nucleus were considered positive (Figure 1). For statistical reasons, in order to analyze the overall survival of patients and clinicopathologic parameters, the mean values of the staining percentages of $\mathrm{MSH} 2$ were used in study.

\section{Statistical analysis}

All data were transferred to SPSS 17.0 software (SPSS Inc., Chicago, Illinois, USA) and subjected to specific tests. The Kolmogorov-Smirnov test was used to determine whether the distribution of continuous variable was normal. The analysis of $\mathrm{MSH} 2$ protein expression in tissues assumed non-parametrical distribution, and comparisons between groups were performed using the MannWhitney test. The prognostic significance of all covariates (clinicopathologic factors and $\mathrm{MSH} 2$ protein immunoexpression) for overall survival data were evaluated using Kaplan-Meyer test and Cox regression models. Associations among variables were considered significant when the confidence level was $>95 \%(p<0.05)$.

\section{RESULTS}

The immunohistochemical evaluation showed that MHS2 protein was detected only in the nucleus of malignant epithelial cells. In all HNSCC samples investigated, it was noted that the invasive fronts exhibited a higher number of cancer cells with a strong nuclear signal (Figure 1). Immunopositivity for $\mathrm{MSH} 2$ protein was noted in $96.4 \%$ of samples (mean \pm s.d. and median: $81.5 \% \pm 21.5 \%$ and $90 \%$, respectively). Table 1 shows bivariate comparisons between the clinicopathologic covariates and the mean values of $\mathrm{MSH} 2$ immunohistochemical expression. No clinicopathologic covariates exhibited a significant association with expression of the MSH2 protein.

In overall survival analysis, HNSCC patients
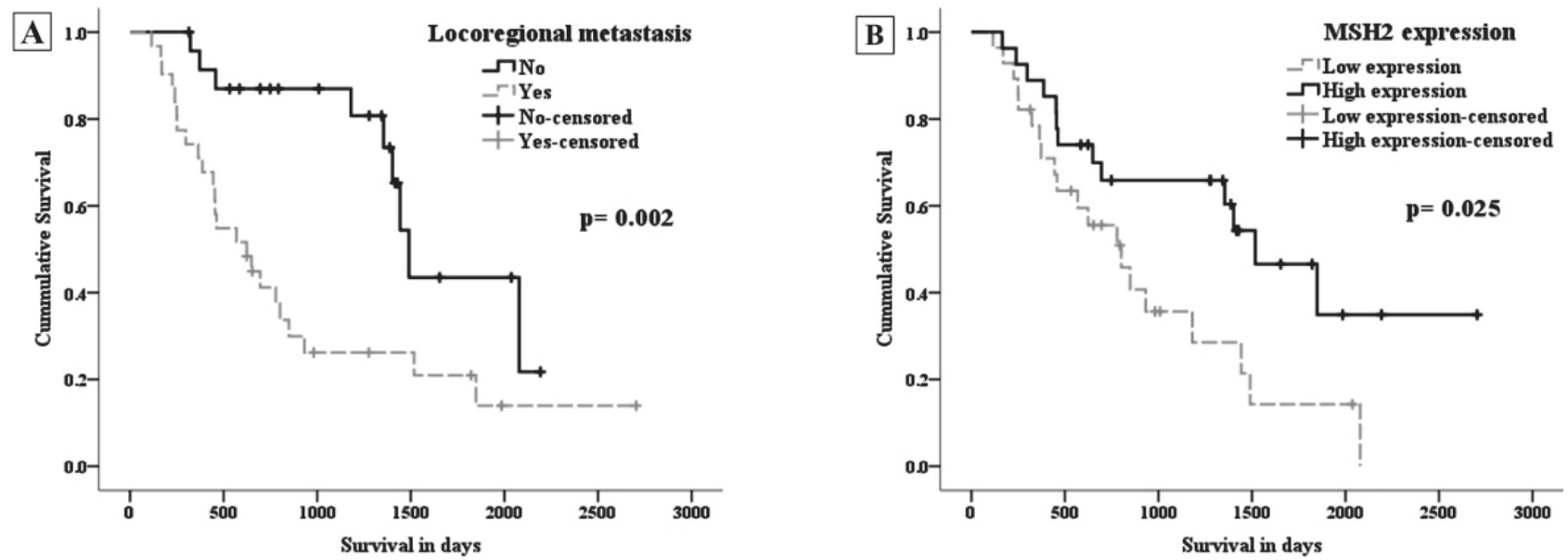

Figure 2- Overall survival analysis in head and neck squamous cell carcinoma patients using Kaplan-Meier survival curves after 2704 days, according to locoregional metastatic disease (A) and MSH2 protein expression (B). Differences between groups were evaluated by the log-rank test

Table 2- Overall survival for the head and neck squamous cell carcinoma patients of this study using Cox regression analysis

\begin{tabular}{|c|c|c|c|c|}
\hline \multirow[t]{2}{*}{ Covariates } & \multicolumn{3}{|c|}{$95 \% \mathrm{Cl}$} & \multirow[b]{2}{*}{$\mathbf{p}$} \\
\hline & OR & Lower & Upper & \\
\hline \multicolumn{5}{|c|}{ Anatomical Site } \\
\hline Anterior & Referent & & & \\
\hline Posterior & 2.120 & 0.216 & 1.029 & 0.059 \\
\hline \multicolumn{5}{|c|}{ Locoregional Metastasis } \\
\hline No & Referent & & & \\
\hline Yes & 4.949 & 2.045 & 11.979 & $0.000^{*}$ \\
\hline \multicolumn{5}{|c|}{ MSH2 Expression } \\
\hline High & Referent & & & \\
\hline Low & 2.943 & 1.212 & 7.142 & $0.032^{*}$ \\
\hline
\end{tabular}


were followed for a period from 116 to 2704 days (mean: $929.1 \pm 622.8$ days and median: 749 days). It was noted that 22 patients $(40 \%)$ were alive and 33 patients $(60 \%)$ died from disease at the end of the period. Patients who died without evidence of recurrence/metastasis were considered censored by the last clinical evaluation. In the bivariate analysis (Kaplan-Meyer curves), the covariates locoregional metastatic disease $(p=0.002)$ and low expression of MSH2 protein $(p=0.025)$ exhibited a significant association with poor overall survival (Figure 2). Subsequently, using Cox's regression multivariate models, significant differences were again noted when we tested the relationship between the covariates of locoregional metastasis (OR=4.949; CI 95\%=2.045-11.979; $p<0.001)$ and low expression of $\mathrm{MSH} 2(\mathrm{OR}=2.943 ; \mathrm{CI}$ $95 \%=1.212-7.142 ; p=0.032)$, with a worse overall survival (Table 2 ).

\section{DISCUSSION}

The mismatch repair pathway is responsible for correcting base substitution mismatches and insertion-deletion mismatches generated during DNA replication or recognizing genetic damage ${ }^{14,20}$. $\mathrm{MSH} 2$ is the most abundantly expressed mismatch repair protein and its inactivation can have profound pathologic consequences on DNA, particularly in microsatellite sequences, rendering them dysfunctional due to instability. Importantly, the presence of this type of DNA damage is considered to be an established biomarker for loss of mismatch repair activities in cancer cells $s^{6,22}$. Notably, few data are available about the role of MSH2 gene status or tissue expression for both upper aerodigestive tract mucosa carcinogenesis and for the progression of $\mathrm{HNSCC}^{7,27,29}$. In this present study, similar with findings of other human cancers studies that showed a low frequency of MSH2 immunonegativity (microsatellite instabilityhigh phenotype) in different human cancers ${ }^{5,18,19}$, we noted a down-regulation of MHS2 protein expression in approximately $9 \%$ of HNSCC samples. Different mechanisms may lead to loss of $\mathrm{MSH} 2$ protein expression, such as mutation in the $\mathrm{MSH} 2$ gene itself that leads to a lack of expression of this protein or to the expression of a truncated, non-functional form ${ }^{9}$. Another mechanism could be $\mathrm{MSH} 2$ gene promoter hypermethylation which can result in its transcriptional silencing ${ }^{15}$.

HNSCC patients frequently exhibit low rates of overall and disease-free survival ${ }^{4,10}$. In the present study, bivariate and multivariate analysis showed that HNSCC patients whose malignancy exhibited low protein expression of $\mathrm{MSH} 2$ and locoregional metastasis had a worse overall survival. Reduced $\mathrm{MSH} 2$ protein expression has also been shown to be of unfavorable prognostic value for prostate cancer $^{30}$, soft tissue sarcoma ${ }^{28}$, and biliary tract carcinoma ${ }^{11}$. Unfortunately, in a variety of human cancers, data on the prognosis of down-regulation of MSH2 expression are still contradictory $5,12,13,17,19,25$. Taking into account HNSCC7, the prognostic value of loss of MSH2 protein expression is unclear, mainly because the few existing studies have presented an insufficient number of patients or perhaps because squamous cell carcinomas from the different anatomic sites of the upper aerodigestive tract seem to exhibit distinct risk factors (environmental and genetic/epigenetic factors), clinical presentations, and outcomes, which may influence the evaluation of potential prognostic markers. According to our findings, the down-regulation of $\mathrm{MSH} 2$ and consequent loss of mismatch repair activities in transformed cells could promote an increased tendency of the genome to acquire mutations in genes associated with maintenance and replication of the genome, inducing in cancer cells a more aggressive phenotype and resulting in a worse prognosis for HNSCC patients. Finally, we confirmed that HNSCC individuals presenting with locoregional metastatic disease also had a poor overall survival. This finding is consistent with fundamental concepts that lymph node status is the most important predictor of survival ${ }^{16}$, which is confirmed in our population of head and neck carcinoma patients.

Our study, however, has a number of limitations such as the small sample size and the typical difficulties of cross-sectional study design to establish causal inference. Unfortunately, it was not possible to investigate the participation of other genetic or epigenetic disturbances that could interfere with the expression and functional activity of $\mathrm{MSH} 2$. Otherwise, our findings show that the immunohistochemical expression of $\mathrm{MSH} 2$ protein seems to contribute to the identification of patients who had a poor prognosis. These findings might be useful for selecting HNSCC patients for adjuvant radiotherapy/chemotherapy protocols. However, future large clinical and molecular studies are needed to foster a better understanding about the reliability of $\mathrm{MSH} 2$ protein as an indicator of biological behavior of HNSCC or as a potential molecular therapeutic target for this type of cancer.

\section{CONCLUSION}

In conclusion, this study showed that reduced MSH2 expression in HNSCC tissues was associated with poor overall survival for patients. This low expression of $\mathrm{MSH} 2$ might contribute to a higher genomic instability and an increase in molecular disturbances resulting in a worse prognosis for patients. 


\section{COMPETING INTERESTS}

The authors declare no competing interests.

\section{ACKNOWLEDGEMENTS}

The authors are grateful for support from Minas Gerais Foundation Research (FAPEMIG) and National Council for Scientific and Technological Development (CNPq). This study was supported by research grant (CNPq - 470331/2010-0).

\section{REFERENCES}

1- Bansal S, Sircar K, Joshi SK, Singh S, Rastogi V. A comparative study of p53 expression in hyperplastic, dysplastic epithelium and oral squamous cell carcinoma. Braz J Oral Sci. 2010;9(2):85-8. 2- Baross-Francis A, Andrew SE, Penney JE, Jirik FR. Tumors of DNA mismatch repair-deficient hosts exhibit dramatic increases in genomic instability. Proc Natl Acad Sci U S A. 1998;95(15):873943.

3- Bryne M, Koppang HS, Lilleng R, Kjaerheim A. Malignancy grading of the deep invasive margins of oral squamous cell carcinomas has high prognostic value. J Pathol. 1992;166(4):37581.

4- Cooper JS, Porter K, Mallin K, Hoffman HT, Weber RS, Ang KK, et al. National Cancer Database report on cancer of the head and neck: 10-year update. Head Neck. 2009;31(6):748-58.

5- Cooper WA, Kohonen-Corish MR, Chan C, Kwun SY, McCaughan $B$, Kennedy $C$, et al. Prognostic significance of DNA repair proteins MLH1, MSH2 and MGMT expression in non-small-cell lung cancer and precursor lesions. Histopathology. 2008;52(5):613-22.

6- Cox EC, Degnen GE, Scheppe ML. Mutator gene studies in Escherichia coli: the mutS gene. Genetics. 1972;72(4):551-67. 7- Demokan S, Suoglu Y, Demir D, Gozeler M, Dalay N. Microsatellite instability and methylation of the DNA mismatch repair genes in head and neck cancer. Ann Oncol. 2006;17(6):995-9.

8- Fuzikawa AK, Haddad LA, da-Cunha-Melo JR, Brasileiro-Filho G, Pena SD. Utilization of microsatellites for the analysis of genomic alterations in colorectal cancers in Brazil. Braz J Med Biol Res. 1997;30(8):915-21.

9- Jascur T, Boland CR. Structure and function of the components of the human DNA mismatch repair system. Int J Cancer. 2006;119(9):2030-5.

10- Jemal A, Siegel R, Xu J, Ward E. Cancer statistics, 2010. CA Cancer J Clin. 2010;60(5):277-300.

11- Kohya N, Miyazaki K, Matsukura S, Yakushiji H, Kitajima Y, Kitahara $K$, et al. Deficient expression of $O(6)$-methylguanineDNA methyltransferase combined with mismatch-repair proteins $\mathrm{hMLH} 1$ and $\mathrm{hMSH} 2$ is related to poor prognosis in human biliary tract carcinoma. Ann Surg Oncol. 2002;9(4):371-9.

12- Kouso H, Yoshino I, Miura N, Takenaka T, Ohba T, Yohena T, et al. Expression of mismatch repair proteins, hMLH1/hMSH2, in non-small cell lung cancer tissues and its clinical significance. J Surg Oncol. 2008;98(5):377-83.

13- Kruschewski M, Noske A, Haier J, Runkel N, Anagnostopoulos $\mathrm{Y}, \mathrm{Buhr} \mathrm{HJ}$. Is reduced expression of mismatch repair genes MLH1 and $\mathrm{MSH} 2$ in patients with sporadic colorectal cancer related to their prognosis? Clin Exp Metastasis. 2002;19(1):71-7.
14- Kunkel TA, Erie DA. DNA mismatch repair. Annu Rev Biochem. 2005;74:681-710.

15- Ligtenberg MJ, Kuiper RP, Chan TL, Goossens M, Hebeda KM, Voorendt $M$, et al. Heritable somatic methylation and inactivation of $\mathrm{MSH} 2$ in families with Lynch syndrome due to deletion of the 3' exons of TACSTD1. Nat Genet. 2009;41(1):112-7.

16- Manikantan K, Khode S, Dwivedi RC, Palav R, Nutting CM, Rhys-Evans $P$, et al. Making sense of post-treatment surveillance in head and neck cancer: when and what of follow-up. Cancer Treat Rev. 2009;35(8):744-53.

17- Mylona E, Zarogiannos A, Nomikos A, Giannopoulou I, Nikolaou I, Zervas A, et al. Prognostic value of microsatellite instability determined by immunohistochemical staining of $\mathrm{hMSH} 2$ and hMSH6 in urothelial carcinoma of the bladder. APMIS. 2008;116(1):59-65

18- Nijhuis ER, Nijman HW, Oien KA, Bell A, ten Hoor KA, ReesinkPeters $\mathrm{N}$, et al. Loss of $\mathrm{MSH} 2$ protein expression is a risk factor in early stage cervical cancer. J Clin Pathol. 2007;60(7):824-30. 19- Ohrling K, Edler D, Hallstrom M, Ragnhammar P. Mismatch repair protein expression is an independent prognostic factor in sporadic colorectal cancer. Acta Oncol. 2010;49(6):797-804. 20- Peltomäki P. Role of DNA mismatch repair defects in the pathogenesis of human cancer. J Clin Oncol. 2003;21(6):1174-9. 21- Pindborg JJ, Wahi PN. Histological typing of cancer and precancer of the oral mucosa. Berlin: Springer; 1997.

22- Plotz G, Piiper A, Wormek M, Zeuzem S, Raedle J. Analysis of the human MutL $\alpha$.MutS $\alpha$ complex. Biochem Biophys Res Commun. 2006;340(3):852-9.

23- Ruszkiewicz A, Bennett G, Moore J, Manavis J, Rudzki B, Shen L, et al. Correlation of mismatch repair genes immunohistochemistry and microsatellite instability status in HNPCC-associated tumours. Pathology. 2002;34(6):541-7.

24- Shia J, Ellis NA, Klimstra DS. The utility of immunohistochemical detection of DNA mismatch repair gene proteins. Virchows Arch. 2004;445(5):431-41.

25- Shih KK, Garg K, Levine DA, Kauff ND, Abu-Rustum NR, Soslow $R A$, et al. Clinicopathologic significance of DNA mismatch repair protein defects and endometrial cancer in women 40 years of age and younger. Gynecol Oncol. 2011;123(1):88-94.

26- Sobin LH. TNM: evolution and relation to other prognostic factors. Semin Surg Oncol. 2003;21(1):3-7.

27- Souza LR, Fonseca-Silva T, Pereira CS, Santos EP, Lima LC, Carvalho HA, et al. Immunohistochemical analysis of p53, APE1, $\mathrm{hMSH} 2$ and ERCC1 proteins in actinic cheilitis and lip squamous cell carcinoma. Histopathology. 2011;58(3):352-60.

28- Taubert HW, Bartel F, Kappler M, Schuster K, Meye A, Lautenschläger $\mathrm{C}$, et al. Reduced expression of $\mathrm{hMSH} 2$ protein is correlated to poor survival for soft tissue sarcoma patients. Cancer. 2003;97(9):2273-8.

29- Theocharis S, Klijanienko J, Giaginis C, Rodriguez J, Jouffroy T, Girod A, et al. Expression of DNA repair proteins, MSH2, MLH1 and MGMT in mobile tongue squamous cell carcinoma: associations with clinicopathological parameters and patients' survival. J Oral Pathol Medi. 2011;40(3):218-26.

30- Velasco A, Hewitt SM, Albert PS, Hossein M, Rosenberg $H$, Martinez C, et al. Differential expression of the mismatch repair gene hMSH2 in malignant prostate tissue is associated with cancer recurrence. Cancer. 2002;94(3):690-9. 